\title{
Expression of colonic antigens by goblet and columnar epithelial cells in ileal pouch mucosa: Their association with inflammatory change and faecal stasis
}

\author{
A P Campbell, M N Merrett, M Kettlewell, N J Mortensen, D P Jewell
}

\begin{abstract}
Aims-To investigate colonic metaplasia of goblet and columnar epithelial cells in ileal pouch mucosa; to correlate this with the degree of morphological and inflammatory change; and to assess whether such changes are related to the presence of faecal stasis.

Methods-Biopsy specimens of ileal pouch mucosa were taken from 31 patients ( 30 with ulcerative colitis, one with familial adenomatous polyposis) either before (eight patients) or after (23 patients) ileostomy closure. A simple morphological technique was used to assess changes in villous height. Inflammatory change was estimated using an established scoring system for pouchitis, and acquisition of colonic antigens was determined by immunohistochemistry using three monoclonal antibodies which recognise components of the two major epithelial cell types in the colorectum. The degree of staining with the monoclonal antibodies was graded and the grades correlated with an index of villous atrophy and with the inflammatory scores.
\end{abstract}

Results-Five of eight (63\%) preclosure and 15 of 23 (65\%) post-closure biopsy specimens showed increased staining with an antibody against components of columnar epithelial cells. One of eight $(12 \%)$ pre-closure and 15 of 23 (65\%) post-closure biopsy specimens stained with an antibody for colonic mucin. Although both types of staining showed a positive correlation with the pouchitis score, they also occurred in the absence of inflammation.

Conclusions-Both goblet and columnar cells acquire colonic characteristics which are incomplete, but may represent a true adaptive response as they can develop in the absence of inflammation. As the change in goblet cells occurs after ileostomy closure, faecal stasis is likely to be a major contributory factor. Changes in columnar cells may occur before ileostomy closure in the absence of faecal stasis.

(F Clin Pathol 1994;47:834-838)
Acquisition of colonic type characteristics by ileal pouch mucosa is well recognised. Morphological and histochemical changes can be demonstrated in over $90 \%$ of pouch biopsy specimens. ${ }^{12}$ Despite this, complete colonic metaplasia does not occur, because small bowel characteristics, such as disaccharidase activity, are retained by the pouch mucosa. ${ }^{3}$ Faecal stasis within the pouch may be an important aetiological factor in the genesis of the colonic phenotype as: (1) colonic characteristics are only found following ileostomy closure $^{4} ;(2)$ they are most pronounced on the posterior wall of the pouch where there is maximal stasis ${ }^{2}$; and (3) similar mucosal changes can be seen in terminal ileum proximal to Crohn's strictures. ${ }^{5}$ However, factors other than stasis must also be important as there does not seem to be any correlation between the efficiency of pouch emptying and the severity of any of the mucosal changes. ${ }^{4}$

Previous studies have largely been confined to changes occurring in goblet cells, with little attention being given to the more numerous columnar epithelial cells. The aims of this study were: (1) to investigate the degree of colonic phenotypic change in pouch mucosa using three monoclonal antibodies which recognise components of the two major epithelial cell types in the colorectum-goblet and columnar cells - and to correlate this with the severity of morphological and inflammatory change within the pouch; (2) to confirm previous findings that changes in goblet cells only occur after ileostomy closure; and; (3) to assess whether any changes in the columnar cells occur before or after ileostomy closurewhether they are related to the presence of faecal stasis.

\section{Methods}

This study was approved by the Central Oxford Research Ethics Committee. Pouch biopsy specimens were assessed from 31 patients (30 with ulcerative colitis and one with familial adenomatous polyposis). Biopsy specimens from eight patients were taken before and from 23 after (eight weeks to eight years) ileostomy closure. All biopsy specimens were taken from the posterior wall of the pouch $10 \mathrm{~cm}$ above the dentate line. They were compared with nine cases of active 
ulcerative colitis (six biopsy specimens, three resections) as well as normal large bowel ( $\mathrm{n}=$ 2 ) and normal terminal ileum $(n=7)$ taken from specimens resected for carcinoma. Immunohistochemistry was carried out on $5 \mu \mathrm{m}$ frozen sections with the primary monoclonal antibodies PR1A3, 3A5, and 5D567 (courtesy of the Imperial Cancer Research Fund, London) (table 1), using a three stage immunoperoxidase technique modified from that described by Mason and Sammons. ${ }^{8}$ PR3A5 and 5D5 react with constituents of mucus glycoproteins. In the case of PR3A5 this is a colon specific form of $\mathrm{O}$-acetyl sialic acid. PR1A3 reacts strongly with colonic columnar cells but only shows focal weak positivity with normal terminal ileum. The antibodies were supplied as culture supernatant fluid preserved with $0.05 \%$ azide and were used neat. Sections were thawed, fixed in acetone for 10 minutes, and dried in air for at least 15 minutes. Endogenous peroxidase activity was blocked by immersing the slides

Table 1 Results of staining with monoclonal antibodies PR5D5, 3A5, and $1 A 3$

\begin{tabular}{|c|c|c|c|c|c|}
\hline Antibody & $\begin{array}{l}\text { Immunohistochemical } \\
\text { specificity in normal colon }\end{array}$ & $\begin{array}{l}\text { Normal } \\
\text { colon and } \\
\text { active UC }\end{array}$ & $\begin{array}{l}\text { Normal } \\
\text { terminal } \\
\text { ileum }\end{array}$ & $\begin{array}{l}\text { Pre- } \\
\text { closure } \\
\text { pouch }\end{array}$ & $\begin{array}{l}\text { Post- } \\
\text { closure } \\
\text { pouch }\end{array}$ \\
\hline PR5D5 & $\begin{array}{l}\text { Goblet cell mucus } 70 \text { kilodaltons } \\
\text { protein/glycoprotein }\end{array}$ & $\begin{array}{l}11 / 11 \\
3+\end{array}$ & $\begin{array}{l}7 / 7 \\
3+\end{array}$ & $\begin{array}{l}8 / 8 \\
3+\end{array}$ & $\begin{array}{l}23 / 23 \\
3+\end{array}$ \\
\hline PR3A5 & $\begin{array}{l}\text { Goblet cell mucus, } \\
\text { membranes, brush border, } \\
>200-43 \text { kilodaltons. } \\
\text { Colon specific } \\
\text { O-Acetyl sialic acid }\end{array}$ & $\begin{array}{l}11 / 11 \\
3+\end{array}$ & $\begin{array}{l}7 / 7 \\
0\end{array}$ & $\begin{array}{l}1 / 8 \\
1+\end{array}$ & $\begin{array}{l}15 / 23 \\
1+\text { to } 2+\end{array}$ \\
\hline PR1A3 & $\begin{array}{l}\text { Columnar cell brush border } \\
\text { and terminal bar region }\end{array}$ & $\begin{array}{l}11 / 11 \\
3+\end{array}$ & $\begin{array}{l}7 / 7 \\
0 / 1+\end{array}$ & $\begin{array}{l}5 / 8 \\
2+\text { to } 3+\end{array}$ & $\begin{array}{l}15 / 23 \\
2+\text { to } 3+\end{array}$ \\
\hline
\end{tabular}

$\mathrm{UC}=$ ulcerative colitis

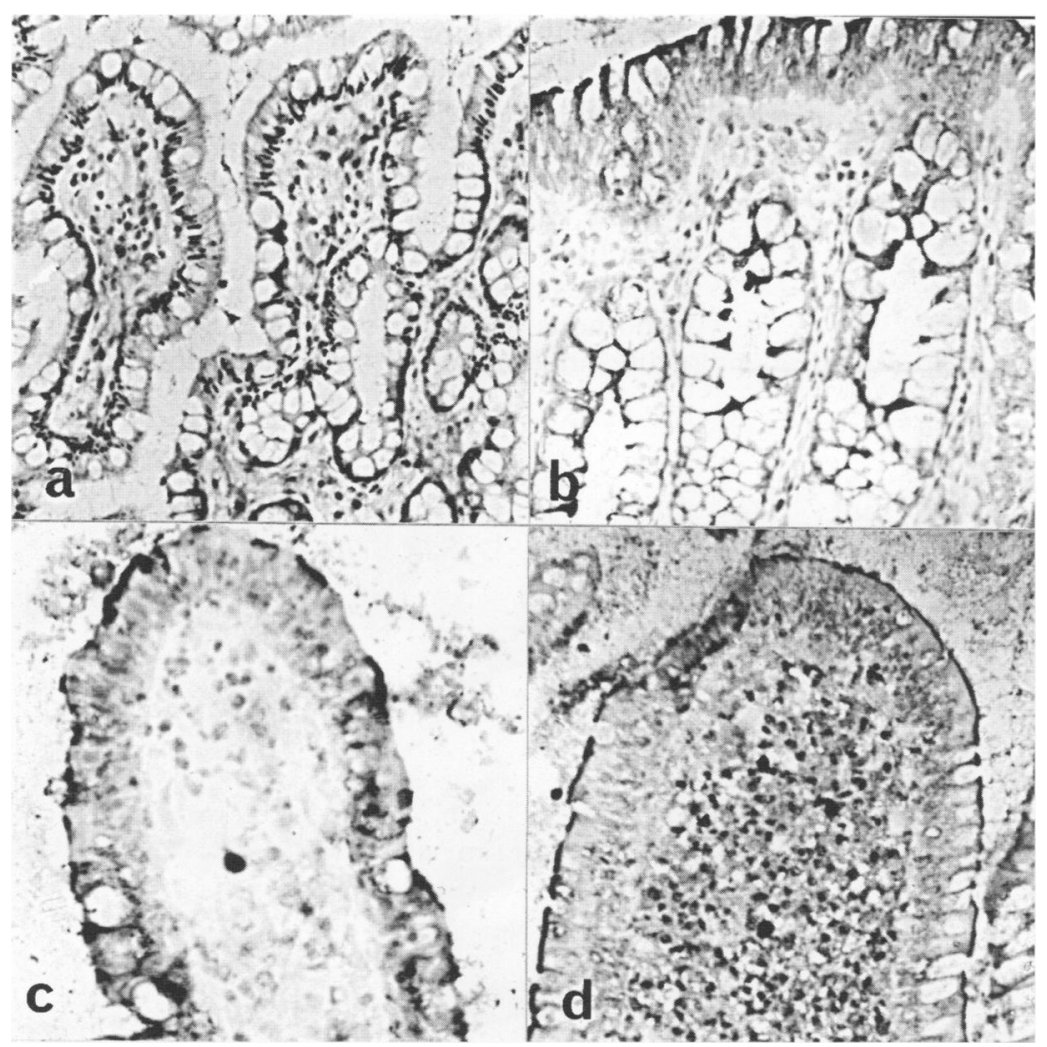

Figure 1 Staining of columnar epithelial cells with PR1A3 (a) normal terminal ileum (negative); (b) normal colon (positive); (c) pre-closure pouch biopsy specimen (positive); (d) post-closure pouch biopsy specimen (positive). in a solution of $3 \%$ hydrogen peroxide in $0 \cdot 1 \%$ sodium azide. After washing in TRISbuffered saline (TBS) the sections were exposed to either the primary antibody or to TBS alone for one hour. They were then sequentially incubated for 30 minutes each with rabbit anti-mouse immunoglobulin (Dakopatts UK) diluted 1 in 50 with a 1 in 3 solution of normal swine serum in TBS and peroxidase conjugated swine anti-rabbit immunoglobulin (Dakopatts UK) diluted 1 in 100. The end product was visualised with diaminobenzidine $(0.5 \mathrm{mg} / \mathrm{ml})$ in the presence of $0.03 \%$ hydrogen peroxide. The sections were lightly counterstained with haematoxylin, dehydrated in alcohol, cleared in xylene and mounted in DPX (BDH laboratory supplies). Tissue from the normal large bowel served as a positive control. All sections were assessed by a single observer (AC) who did not know whether the pouch biopsy specimens were taken before or after closure. Strength of staining of goblet and columnar cells was graded from 0 to $3+$, where 0 was negative and $3+$ was strongly positive involving most of the cells. Loss of villous height in the pouch biopsy specimens was assessed in the following manner. Measurements of total mucosal thickness (TMT) and crypt depth (CD) were taken from routine haematoxylin and eosin stained sections using a calibrated eye piece (Leitz) at a magnification of $\times 100$. Measurements were only taken where the muscularis mucosae could be clearly identified ( 17 biopsy specimens, four before and 13 after closure). A minimum of three measurements were taken per specimen (mean $3 \cdot 778$, median 3, range 3-9) and the mean values used to calculate the villous height $(\mathrm{VH})$ and an index of villous atrophy (VH/TMT). ${ }^{9}$ Acute (ulceration 0-3, neutrophil polymorph infiltration $0-3$ ) and chronic (loss of villous height $0-3$, chronic inflammatory cell infiltrate 0-3) inflammatory changes were assessed by the same observer, using an established scoring system for pouchitis. ${ }^{110}$

Grouped data were expressed as median and range. All tests of significance were two sided. Differences between measurements were assessed by the Wilcoxon rank sum test and the Mann-Whitney $U$ test with corrections for tied values (pouchitis scores). The significance of correlation was determined by the Spearman rank correlation coefficient. For all statistical analyses the level of significance was taken as $95 \%$ where $p<0.05$.

Results (table 1)

All biopsy specimens and control samples were strongly positive with the antibody 5D5. Normal colon and colon from the nine cases of ulcerative colitis also showed strong positive staining with PR1A3 and 3A5. Normal terminal ileum was weakly positive with PR1A3 but was completely negative with PR3A5. Five out of eight (63\%) pre-closure and 15 out of $23(65 \%)$ post-closure biopsy specimens showed an increased intensity of staining with PR1A3 (fig 1). Seven of the 
eight $(88 \%)$ pre-closure biopsy specimens were completely negative with PR3A5 but one showed positive staining in occasional goblet cells. Fifteen out of $23(65 \%)$ post-closure biopsy specimens showed variable degrees of positivity with this antibody (fig 2). Total mucosal thickness, crypt depth, and the index of villous atrophy were all significantly increased in the post-closure specimens compared with the pre-closure pouch biopsy specimens $(p<0.01)$ (table 2$)$, but did not show any correlation with PR1A3 and 3A5 expression. The index of villous atrophy correlated well with the subjective assessment of villous height used in the pouchitis score ( $\mathrm{rs}=$ $-0.632 ; p=0.007)$. There were no significant differences in the pouchitis scores between biopsy specimens before and after closure, and only one of the post-closure specimens fulfilled the histological criteria for pouchitis (table 3). However, there was a significant correlation between increasing pouchitis score and increased staining with both PR1A3 and 3A5 (rs $=0.406,0.411$; and $\mathrm{p}=0.023$ and 0.021 , respectively) (fig 3 ). Increased staining with PR1A3 correlated with both increasing score for chronic inflammation ( $r s=0.410 ; p=0.022$ ) and with the subjective assessment of loss of villous height

Table 2 Comparing indices of villous atrophy (VH/TMT) for pre- and post-closure pouch biopsy specimens

\begin{tabular}{lcc}
\hline & $\begin{array}{l}\text { Pre-closure } \\
(n=4)\end{array}$ & $\begin{array}{l}\text { Post-closure } \\
(n=13)\end{array}$ \\
\hline $\begin{array}{l}\text { Median index } \\
\text { Range }\end{array}$ & $\begin{array}{l}0.302 \\
0.202-0.382\end{array}$ & $\begin{array}{l}0.483 \\
\text { p value }\end{array}$ \\
\hline
\end{tabular}

Table 3 Comparing total pouchitis scores for pre- and post-closure pouch biopsy specimens

\begin{tabular}{lll}
\hline & $\begin{array}{l}\text { Pre-closure } \\
(n=8)\end{array}$ & $\begin{array}{l}\text { Post-closure } \\
(n=23)\end{array}$ \\
\hline $\begin{array}{l}\text { Median score } \\
\text { Range }\end{array}$ & 2 & 3 \\
p value & $0-6$ & $0-8$ \\
\hline
\end{tabular}
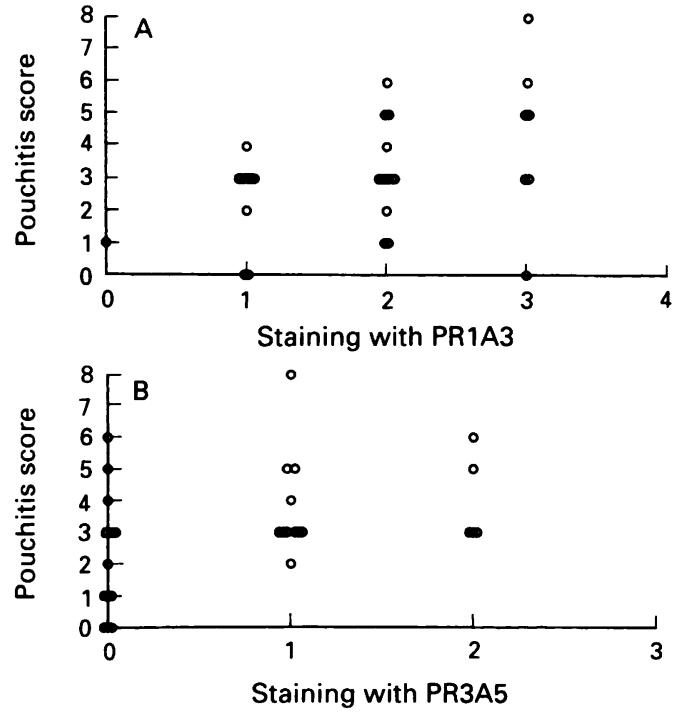

Figure 3 Association between pouchitis score and (a) staining with PR1A3 and (b) PR3A5.

( $\mathrm{rs}=0.367 ; \mathrm{p}=0.042$ ). Increased staining with PR3A5 showed greater correlation with the subjective assessment of loss of villous height ( $r s=0.468 ; p=0.008$ ) than with the score for chronic inflammation ( $\mathrm{rs}=0.232$; $\mathrm{p}=0 \cdot 208, \mathrm{NS})$.

\section{Discussion}

Restorative proctocolectomy with ileal pouchanal anastomosis is now a well established form of treatment for patients with ulcerative colitis, familial adenomatous polyposis, and other colonic disorders such as Hirschprung's disease and idiopathic constipation. ${ }^{23}$ Formation of the ileal reservoir results in phenotypic changes in the small bowel mucosa. These include loss of villous height and crypt hyperplasia together with a change from small intestinal type sialomucin to colonic type sulphomucin. This evidence has been used to support the concept of "colonic metaplasia" in the ileal pouch mucosa. Such a hypothesis is attractive. The syndrome of acute inflammation and ulceration in the
Figure 2 Showing staining of goblet cells with PR3A5 (a) normal colon (positive); (b) pre-closure pouch biopsy specimen (negative); (c) post-closure pouch biopsy (positive).

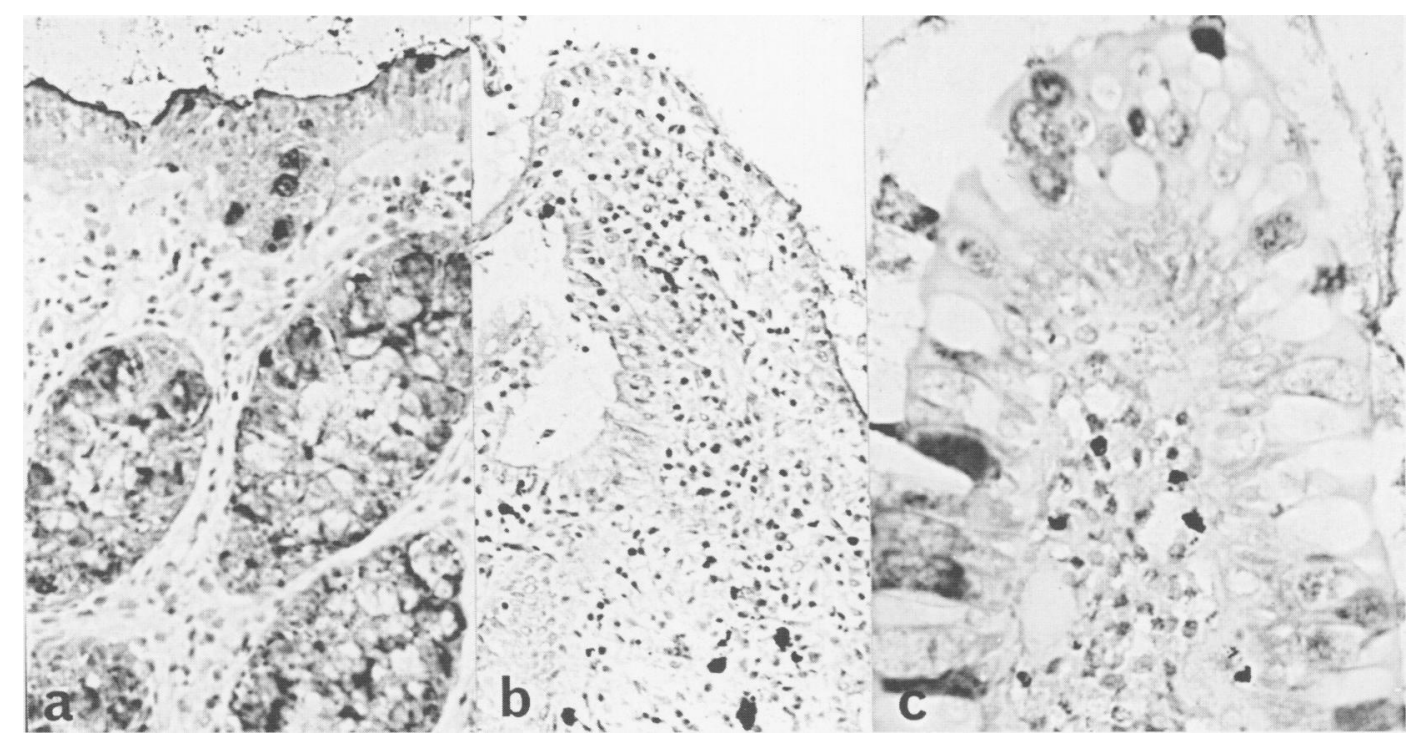


pouch-"pouchitis" is almost entirely confined to patients with ulcerative colitis. Pouches showing colonic metaplasia might be useful as a model in which to study the aetiology of ulcerative colitis because possible pathogenic mechanisms can be studied from the time of pouch formation. However, despite the acquisition of some colonic features, ileal function seems to be quite well maintained in the pouch. Pouch mucosa retains disaccharidase activity (sucrase isomaltase) in the brush border, and nutritional studies on patients with pouchitis have shown normal fat absorption and serum folate concentration with decreased absorption of xylose, lactulose, and iron in only a proportion of cases (up to $30 \%$ ). ${ }^{11}{ }^{12}$ Colonic metaplasia, if present, must therefore be incomplete.

The main functional difference between pouches and conventional ileostomies (in which "colonic metaplasia" is not seen) is the presence of faecal stasis. In general, metaplastic changes only seem to occur following ileostomy closure and they stabilise within three months. ${ }^{4} \mathrm{~A}$ recent study has shown that "colonic metaplasia" is greatest on the posterior wall of the pouch where stasis is maximal. ${ }^{2}$ Similar changes can be seen proximal to Crohn's strictures. ${ }^{5}$ However, pouch emptying studies have not shown any relation between incomplete emptying and the degree of "colonic metaplasia" or of "pouchitis".410 Therefore, although faecal stasis probably contributes to the changes seen in pouch mucosa, other factors such as bacterial overgrowth may be involved. The focal distribution and incomplete nature of colonic metaplasia seen in biopsy specimens from multiple sites in the ileal pouch prompted Shepherd et al to hypothesise that acquisition of colonic type mucin is a non-specific response to pouch inflammation rather than representing true colonic metaplasia. ${ }^{2}$

Previous studies have tended to concentrate on changes in the goblet cell mucin, although acquisition of colonic ultrastructural characteristics in pouch mucosa (cell type not specified) has been described. ${ }^{13}$ We were able to investigate changes occurring in both goblet and columnar cells in pouch mucosa using the monoclonal antibodies PR1A3, 3A5, and 5D5 (table 1), and to assess these in biopsy specimens taken either before or after ileostomy closure. The antibodies used were developed by Richman and Bodmer as markers for colonic tumour differentiation and characterisation. ${ }^{67}$ PR5D5 stains goblet cells throughout the gastrointestinal tract, whereas PR3A5 reacts with colon specific O-acetyl sialic acid and is not present in normal ileum. Shepherd et al have shown that up to $78 \%$ of biopsy specimens from multiple sites in the ileal pouch (after ileostomy closure) show a degree of positive staining with PR3A5. In the present study $65 \%$ of post-closure biopsy specimens from a single site on the posterior wall of the pouch were positive with this antibody. Only one of the pre-closure specimens showed any positivity and then only in occa- sional goblet cells. The patient from whom this biopsy specimen was taken was known to have a pouch-vaginal fistula and the biopsy specimen showed chronic inflammatory changes with a pouchitis score of 5 . In the series as a whole increased staining with PR3A5 correlated with increasing pouchitis score but this seemed to be due to its association with loss of villous height rather than an increase in the amount of chronic inflammation. This finding suggests that while acquisition of colonic type mucin by the pouch may be a non-specific response to inflammation, it may also represent true adaptive change. As in most cases the change to colonic type mucin occurs after ileostomy closure; faecal stasis may be a contributory factor.

PR1A3 reacts with a surface antigen present in the membrane, apical cytoplasmic region, and microvillous brush border of columnar cells on the surface and upper crypts of colonic mucosa. It has only a faint and focal reaction in normal terminal ileum compared with strong diffuse staining in the colon. ${ }^{99 m}$ TC labelled PR1A3 has been used for the imaging of colorectal cancer ${ }^{14}$ but not in the assessment of pouch biopsy specimens. In this study columnar cells showed strong colonic type staining with PR1A3 both before and after pouch closure, indicating that in contrast to the situation in goblet cell mucus, change to a colonic phenotype can occur in columnar cells before ileostomy closure and therefore before exposure to the faecal stream. This finding is further evidence that factors other than faecal stasis may be responsible for acquisition of colonic characteristics within the pouch. As all our patients had a loop ileostomy their pouches may have been exposed to a small quantity of faecal material before ileostomy closure. Although there is unlikely to be major clinically relevant stasis, the bacterial flora of the pouch may become altered at an early stage with consequent adaptive change in the columnar epithelial cells. An altered ratio of anaerobes to aerobes may determine the magnitude of pathological change within the established pouch, but the precise role of bacteria in the acquisition of colonic characteristics by the pouch mucosa and in the pathogenesis of pouchitis remains uncertain. ${ }^{1516}$ As with PR3A5, staining for PR1A3 showed a positive correlation with the pouchitis score. In contrast to the situation for PR3A5, however, there was a significant correlation with the score for chronic inflammation as well as that for loss of villous height. Two of the pre-closure biopsy specimens showing strong staining with PR1A3 had "pouchitis" scores of 5 and 6 (both with acute scores of 1 ), respectively. Although these were not sufficient for a histological diagnosis of "pouchitis" (this requires a total score of $>8$ or an acute score of $>4$ ), they still indicate the presence of moderate chronic inflammatory change. In one of these patients the inflammation was known to be secondary to a pouchvaginal fistula (which has since healed); in the other the aetiology was unknown. Pouch inflammation before ileostomy closure has 
been reported. ${ }^{17}{ }^{18}$ It is rare, of obscure aetiology, and seems only to affect patients with previous ulcerative colitis. Whether it is related to the more common post-closure "pouchitis" is unknown. Crohn's disease, chronic ischaemia, mucosal prolapse and diversion pouchitis have to be excluded. Despite the above, it is unlikely that inflammation alone causes acquisition of colonic antigens by columnar cells as three biopsy specimens (one before, two after closure) with a pouchitis score of 0 also showed increased staining with PR1A3.

Both the index of villous atrophy (VH/TMT) and the degree of staining with PR3A5 and 1A3 showed significant correlations with the subjective assessment of loss of villous height included in the pouchitis score. However, VH/TMT did not show a signifcant correlation with the immunohistochemistry. These disparate findings might be explained by the fact that only 17 biopsy specimens were suitable for morphometric measurements.

In conclusion, staining with antibodies against putative colonic antigens shows acquisition of colonic characteristics by some goblet and columnar epithelial cells in the ileal pouch. Although incomplete, these may represent a true adaptive response as they can develop in the absence of inflammation. Changes in goblet cells occur after ileostomy closure when faecal stasis is likely to be a major contributory factor. On the other hand, adaptive changes in columnar cells may occur before ileostomy closure when factors other than faecal stasis, such as subtle changes in bacterial flora, could be important.

Dr Anne Campbell is in receipt of a Wellcome Training Fellowship.
1 Shepherd NA, Jass JR, Duval I, Moskowitz RL, Nicholls RJ, Morson BC. Restorative proctocolectomy with ileal reservoir: pathological and histochemical study of mucosal biopsy specimens. F Clin Pathol 1987;40:601-7.

2 Shepherd NA, Healey CJ, Warren BF, Richman PI Thomson WHF, Wilkinson SP. Distribution of mucosal pathology and an assessment of colonic phenotypic change in the pelvic ileal reservoir. Gut 1993;34:101-5.

3 de Silva HJ, Millard PR, Kettlewell M, Mortensen NJ, Prince C, Jewell DP. Mucosal characteristics of pelvic ileal pouches. Gut 1991;32:61-5.

4 de Silva HJ, Millard PR, Soper N, Kettlewell M, Mortensen N, Jewell DP. Effects of the faecal stream and stasis on the ileal pouch mucosa. Gut 1991;32: and stasis

5 Merrett $M N$, de Silva HJ, Rhodes JM, Milton JD, Campbell A, Prince C, et al. Colonic type mucin occurs in the ileal pouch and small intestinal Crohn's strictures, the ileal pouch and small intestinal Crohn's strict
but not in coeliac disease. Gut 1991;32:A1254-5.

6 Richman PI, Bodmer WF. Monoclonal antibodies to human colorectal epithelium: markers for differentiation and tumour characterisation. Int $\mathcal{F}$ Cancer 1987;39. 317-28.

7 Richman PI, Bodmer WF. Control of differentiation in human colorectal carcinoma cell lines: epithelial-
mesenchymal interactions. $₹$ Pathol $1988 ; 156: 197-211$.

8 Mason DY, Sammons RE. The labeled antigen method of immunoenzymatic staining. 7 Histochem Cytochem 1979; 27:832-40.

9 Corazza GR, Frazzoni M, Dixon MF, Gasbarrini G. Quantitative assessment of the mucosal architecture of jejunal biopsy specimens: a comparison between linear measurement, stereology, and computer aided microscopy. F Clin Pathol 1985;38:765-70.

10 Moskowitz RL, Shepherd NA, Nicholls RJ. An assessment of inflammation in the reservoir after restorative proctocolectomy with ileoanal ileal reservoir. Int $\mathcal{f}$ Colorect Dis 1986;1:167-74.

11 Mortensen N. Progress with the pouch-restorative proctocolectomy for ulcerative colitis. Gut 1988;29:561-5.

12 Lerch MM, Braun J, Harder M, Hofstadter F, Schumpelick V, Matern S. Postoperative adaptation of the small intestine after total colectomy and J-pouchthe small intestine after total colectomy and J-po

13 Bruce DL, Warren BF, Durdey P, Luckett M, Shepherd NA. Ultrastructural appearances of the pelvic ileal reservoir mucosa. F Pathol 1992;167:109A

14 Granowska M, Mather SJ, Britton KE, Bentley S, Richman P, Phillips RKS, et al. ${ }^{99 m}$ Tc radioimmunoscintigraphy of colorectal cancer. Br $f$ Cancer 1990;62(Suppl X):30-3.

15 Nasmyth DG, Godwin PGR, Dixon MF, Williams NS, Johnston D. Ileal ecology after pouch-anal anastomosis or ileostomy. Gastroenterology 1989;96:817-24.

16 Madden MV, Farthing MJG, Nicholls RJ. Inflammation in ileal reservoirs: "pouchitis". Gut 1990;31:247-9.

17 Warren BF, Bartolo DCC, Collins CMP. Pre-closure pouchitis-a new entity. F Pathol 1990;160:170A.

18 Warren BF, Shepherd NA. The role of pathology in pelvic ileal reservoir surgery. Int $\mathcal{f}$ Colorect Dis 1992;7:68-75. 